Article

\title{
MODIS EVI and LST Temporal Response for Discrimination of Tropical Land Covers
}

\section{Chittana Phompila ${ }^{1,2, *}$, Megan Lewis ${ }^{2, \dagger}$, Bertram Ostendorf ${ }^{2, \dagger}$ and Kenneth Clarke ${ }^{2, \dagger}$}

1 Faculty of Forest, The National University of Laos, Vientiane Capital 0100, Lao PDR;

2 School of Biological Sciences, The University of Adelaide, Adelaide, SA 5005, Australia; E-Mails: megan.lewis@adelaide.edu.au (M.L.); bertram.ostendorf@adelaide.edu.au (B.O.); kenneth.clarke@adelaide.edu.au (K.C.)

$\dagger$ These authors contributed equally to this work.

* Author to whom correspondence should be addressed; E-Mail: chittana.phompila@adelaide.edu.au; Tel.: +618-8313-8112; Fax: +618-8313-6717.

Academic Editors: Clement Atzberger and Prasad S. Thenkabail

Received: 5 March 2015 / Accepted: 7 May 2015 / Published: 13 May 2015

\begin{abstract}
MODIS enhanced vegetation index (EVI) and land surface temperature (LST) are key indicators for monitoring vegetation cover changes in broad ecosystems. However, there has been little evaluation of these indices for detecting changes in a range of land covers in tropical regions. In this study, we investigated the characteristics and seasonal responses of LST and EVI for four different land covers in Lao tropical forests: native forest, rubber plantation, mixed wooded/cleared areas and agriculture. We calculated long-term averages of MODIS LST and EVI 16-day time series and compared their monthly transitions over the seven-year period from 2006 to 2012 . We also tested whether these indices can be used to classify these four land covers. The findings demonstrate the complex interrelationship of LST and EVI and their monthly transitions for different land covers: they each showed distinctly different intra-annual LST and EVI variations. Native forests have the highest EVI, and the lowest LST throughout the year. In contrast, agricultural areas with little or no vegetation cover have the highest LST. The transition of LST/EVI for the land covers other than native forests showed marked seasonality. Linear discriminant analysis (LDA) showed that there was high overall accuracy of separation of land covers by these indices ( $86 \%)$. The encouraging results indicate that the combined use of MODIS LST and EVI holds promise for improving monitoring of changes in a Lao tropical forest.
\end{abstract}


Keywords: vegetation characteristics; temporal response; monthly transition; hysteresis; linear discrimination analysis (LDA); MODIS LST; EVI

\section{Introduction}

Vegetation cover changes in tropical regions are among the most significant contributors to global climate change [1-4]. These changes have resulted in changes in carbon stock, land degradation and rapid loss of biodiversity [1]. Understanding how ecological systems are changing requires effective monitoring of vegetation changes in space and time [5]. Our knowledge of these changing events and processes can be improved using information from satellite observations. The majority of remote sensing approaches to monitoring these changes have used vegetation indices, most commonly the normalized difference vegetation index (NDVI) or enhanced vegetation index (EVI) [1,6,7]. However, many studies have suggested that use of additional parameters such as land surface temperature (LST) improves monitoring of land covers [8-10].

Used together, these indices may be suitable for monitoring land cover change in tropical regions. In tropical regions, EVI is more suitable than NDVI to study vegetation, as it has been shown to have improved sensitivity to high biomass through a de-coupling of the canopy background signal and a reduction in atmospheric influences [11-16]. LST is used to measure the heat energy flux from the Earth's surface [17-20]. It appears to be strongly correlated to the density of the canopy of various land covers [21]. Using a combination of these two parameters can provide insight into surface energy fluxes and vegetation cover changes at regional and global scales $[6,7,11,20]$.

Several studies have applied these indices successfully to detect vegetation dynamics in broad landscapes including boreal, semiarid, arid and temperate forests [6,7,11,18,22-24]. Several studies suggest that the combination of measurements of temperature and vegetation indices provides a better classification and observation of land covers in the African continent [25,26], Sub-Saharan Africa [27] and over the continental United States [28]. The most recent studies also used these two parameters to analyze global vegetation cover changes $[8,29]$. In addition to these studies, LST and NDVI has been used to detect changes in land covers between non-forested and forest areas in Brazilian tropical forests [21]. It was found that LST data can provide key information for classifying non-forested and forest areas, and can be further used for detecting long-term changes in land covers. However, although the combined use of LST and vegetation indices has provided better monitoring of land covers at broad scales, application of LST and EVI in a wider range of land cover types in tropical regions has not been adequately assessed. Frequent cloud cover, high levels of atmospheric water, and aerosol haze can be issues when employing these indices in tropical forest environments [21,30,31]. Furthermore, the vegetation cover and soil exposure for different land uses can vary substantially from dry to wet seasons. Thus, detecting the characteristics, distribution and variation of vegetation cover in tropical forests remains challenging.

In this study, our main goal was to investigate the characteristics and seasonal responses of EVI and LST for four different land covers in a tropical location: native forest, rubber plantation, mixed wooded/cleared areas and agriculture. This allowed us to gain a better understanding of how these 
tropical land covers influence the responses of these indices. We analyzed MODIS EVI and LST 16-day time series for a Lao tropical region over the seven-year period from 2006 to 2012. We compared monthly transitions of EVI and LST data for these four land covers within our study area. We also evaluated whether the combined use of these indices can classify these land covers. This knowledge will be potentially useful for further detection of deforestation in tropical forests, information which is essential for forest management and combating deforestation in developing countries in the tropics.

\section{Methods}

\subsection{Study Area}

The focus of our investigations was the tropical forest lands of Champasack Province, in the south of Lao PDR. The study site covers an area of $2500 \mathrm{~km}^{2}$, from $14^{\circ} 44^{\prime} 20^{\prime \prime} \mathrm{N}$ to $15^{\circ} 25^{\prime} 52^{\prime \prime} \mathrm{N}$ latitude and from $105^{\circ} 42^{\prime} 7^{\prime \prime E}$ to $106^{\circ} 0^{\prime} 30^{\prime \prime E}$ longitude (Figure 1). Comprehensive mapping of land cover types is not yet available for Laos, although monitoring of forest resources and land clearance is a high national priority, calling for development of suitable remote sensing approaches for land cover inventory and monitoring. Champasack Province has experienced rapid changes in land cover in recent years including clearance of native forest and large expansions of rubber plantations. Consequently it provided an ideal study area to test the suitability of our remote sensing land cover discrimination. In addition, we needed independent information to validate the MODIS coarse-resolution analysis. In the absence of comprehensive field data, Google Earth ${ }^{\mathrm{TM}}$ high resolution images were the only available source of land cover information, so our specific study area was determined by the availability of Google Earth images of the same site for two dates, in 2006 and 2012.

This area covers the northern part of the province and includes five administrative districts: Pakse, Xanasomboun, Bachieng, Pathumphon and Phonthong. The study area has relatively flat terrain comprising two different landscapes: about $10 \%$ of the area is upland and $90 \%$ is flat lowland. The altitude ranges from 10 to $922 \mathrm{~m}$, but the majority of land is between 10 and $250 \mathrm{~m}$ above sea level. There are two distinct seasons in this location: rainy (May-October) and dry (November-April). During the rainy season, it is often windy and humidity is high, with average minimum and maximum temperatures of $21^{\circ} \mathrm{C}$ and $31^{\circ} \mathrm{C}$ respectively. Roughly $300-450 \mathrm{~mm}$ of precipitation falls per month in this season. In the dry season, conditions are mostly sunny, average minimum and maximum temperatures are $19{ }^{\circ} \mathrm{C}$ and $35^{\circ} \mathrm{C}$ respectively and there is little rainfall (less than $100 \mathrm{~mm}$ per month). From the high resolution images we identified four main types of land cover: native forest, rubber plantation, mixed wooded/cleared area and agriculture. Agricultural lands mainly comprise areas of irrigated rice cultivation.

\subsection{Satellite Imagery}

The research made use of two Moderate Resolution Imaging Spectroradiometer (MODIS) data products: the 16-day composite time series of EVI (MOD13A2) and the 8-day composite of LST (MOD11A2), from 2006-2012, both of which have a spatial resolution of $1 \mathrm{~km}$. The study area was covered by MODIS tile h28v07. Data was downloaded from the National Administration and Space Aeronautics Administration (NASA) website (http://reverb.echo.nasa.gov/reverb). MODIS data was 
reprojected to WGS84, UTM zone 48 North using the MODIS reprojection tool (version 4.01). Data quality was checked before further analysis and only good quality MODIS EVI and LST data (as rated by the MODIS quality flag) was used to reduce noise in our analysis.

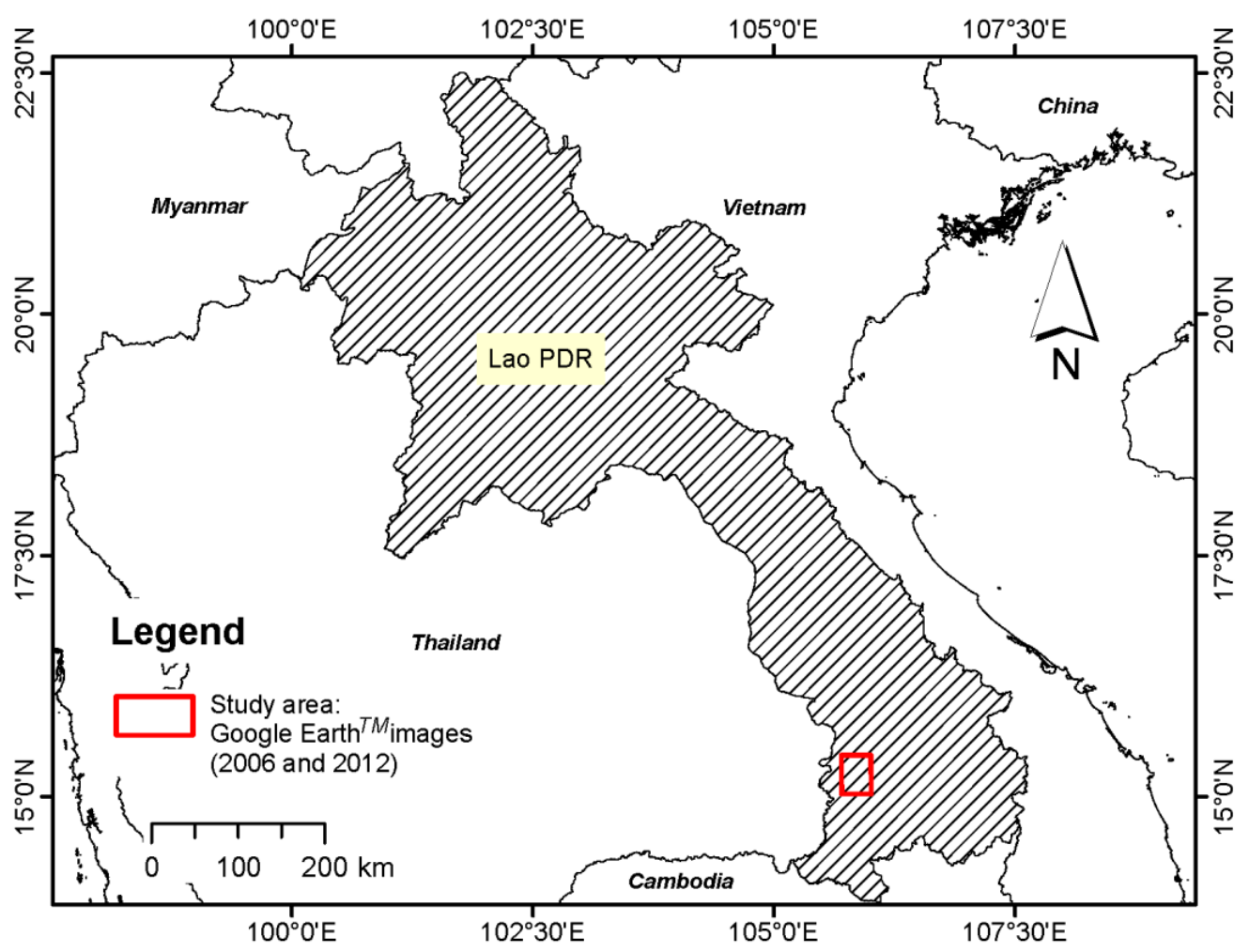

Figure 1. Location of the study area in the south of the Lao PDR.

\subsection{Method Overview}

Two major research components were undertaken: (1) examination of long-term averages of seasonal responses of LST and EVI 16-day composite data and the monthly transitions for the four dominant land cover types, and (2) investigation of the effectiveness of using MODIS LST and EVI data to discriminate and classify these land cover types.

\subsubsection{Temporal Response of LST and EVI for Different Land Cover Types}

We identified the four dominant land cover types on a high resolution colour Google Earth ${ }^{\mathrm{TM}}$ image from 2012: native forest, rubber plantation, mixed wooded/cleared land and agriculture (Table 1, Figures 2 and 3). Their distinguishing features are as follows: (1) native forest is usually a dense and homogeneous canopy of vegetation containing a number of tree species; (2) rubber plantations show consistent canopy patterns and textures comprising similar tree ages, with regular planted tree spacing; (3) mixed wooded/cleared areas are fragmented, usually with low vegetation cover and may include partly cleared areas, with some parts containing a mixture of trees, shrubs, grass and bare soils; and (4) agriculture includes mainly paddy fields and minor areas of shrubs, trees and water. 
Table 1. Description of the four land cover types in the study area.

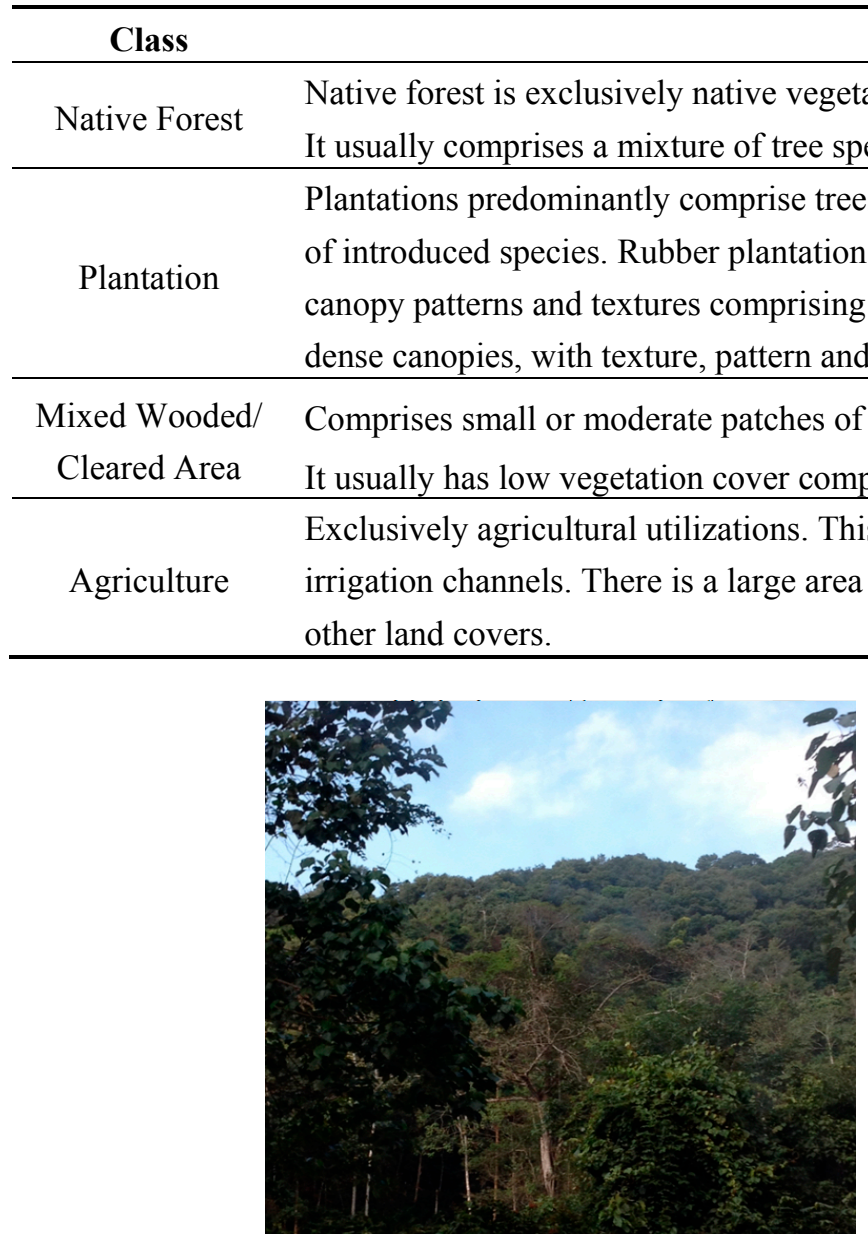

(a)

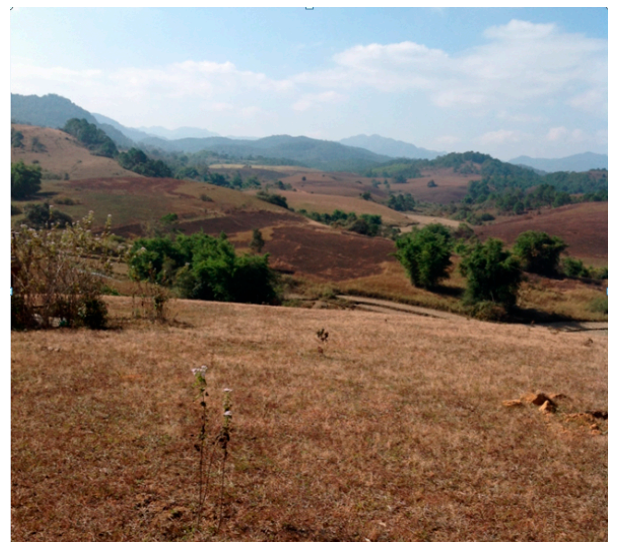

(c)

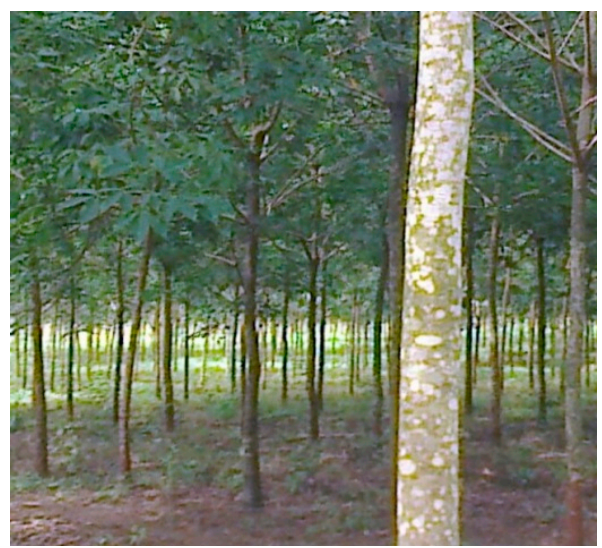

(b)

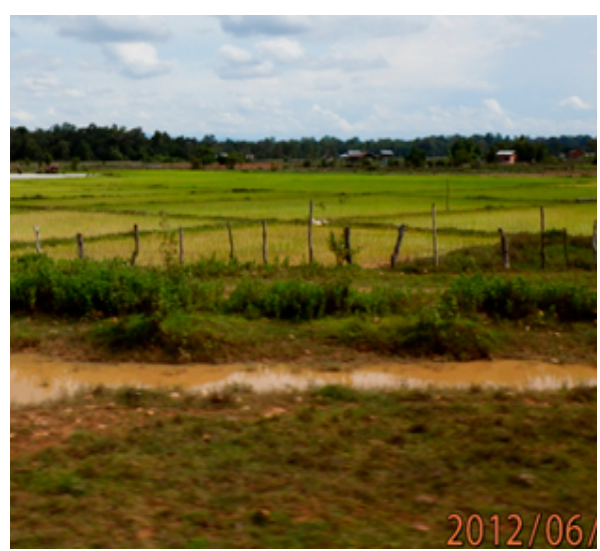

(d)

Figure 2. Photos of the four land covers taken in the study area by Faculty of Forestry team researchers, May-June 2012. (a) native forest, (b) rubber plantation, (c) mixed wooded/cleared area, and (d) agriculture. 


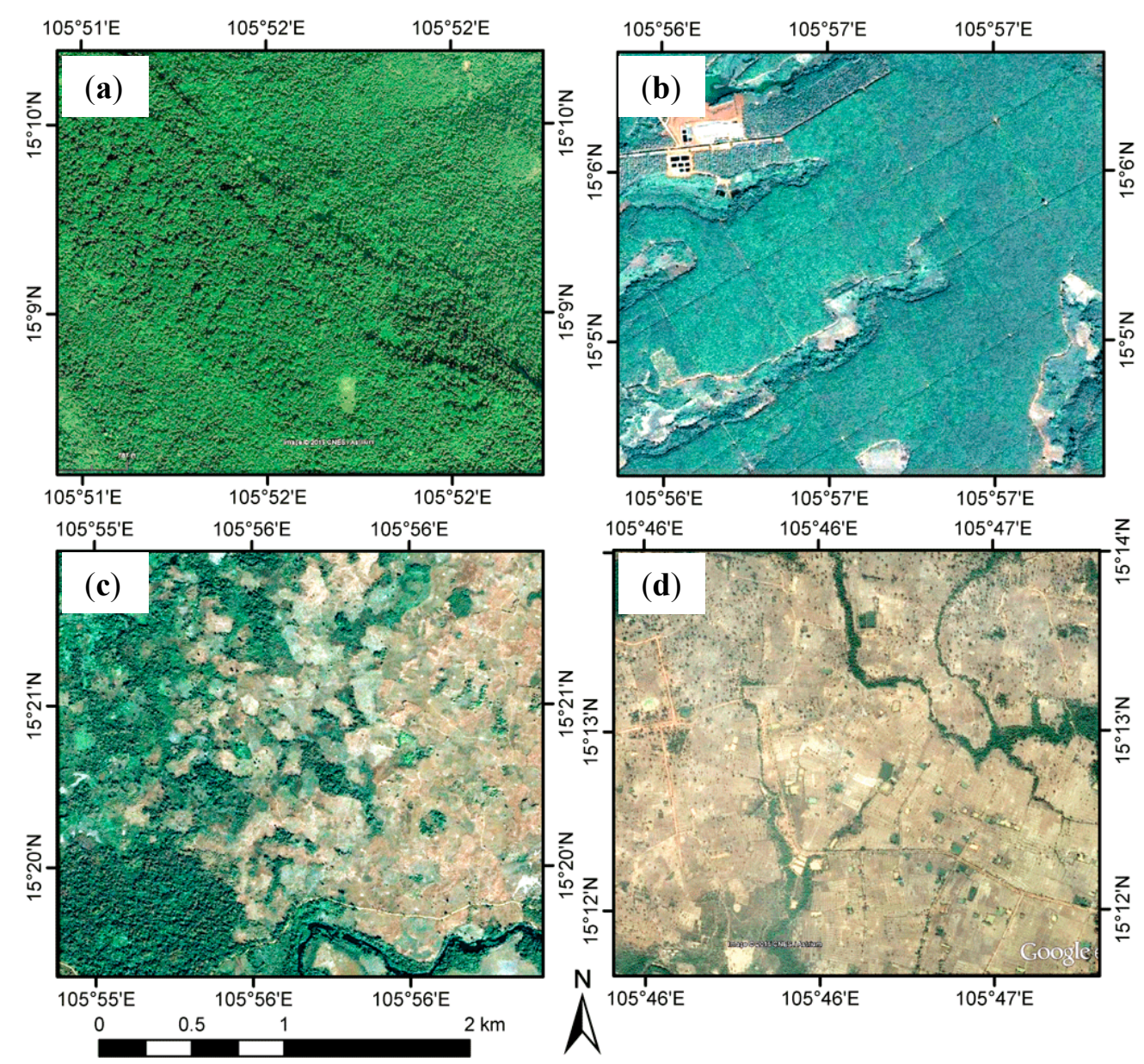

Figure 3. Google Earth ${ }^{\mathrm{TM}}$ images in 2012 representing the four land covers: (a) native forest, (b) rubber plantation, (c) mixed wooded/cleared area, and (d) agriculture.

We digitized the distribution of these four land covers as polygons on the 2012 image. Next, we used the Hawths Analysis Tools for ArcGIS 10.2.1 software to generate 800 random samples of the digitized data, stratified to give 200 samples of each of the four land cover types. To ensure sample representation of each land cover class, we set selection rules. These rules were: (1) each location must be the central point of a MODIS pixel of $1 \times 1 \mathrm{~km}$ and at least $2 \mathrm{~km}$ away from any other selected location; and (2) the land cover must be homogeneous and cover $100 \%$ of the MODIS pixel. These procedures were then repeated for the Google Earth ${ }^{\mathrm{TM}} 2006$ image of the same site. This was to ensure we selected only samples representing the four land covers in both periods (2006 and 2012). Finally, corresponding pixel values of both LST and EVI time series (2006-2012) were extracted from the samples. In total 161 MODIS EVI (23 per year) and 322 LST composite images (46 per year) were used. LST scenes were averaged to 16-day composites to ensure an equivalent number of EVI and LST scenes and dates.

Finally, we calculated long-term averages and standard deviations of LST and EVI for the 16-day composites for the four different land cover types over the period 2006-2012. In addition, we further investigated the monthly transitions of these indices throughout the year for the four land covers. An analysis was undertaken of the hysteresis patterns based on the monthly long-term average of EVI plotted against the monthly long-term average of LST. These plots show the relationship over time of the two indices. 


\subsubsection{Discriminating the Different Land Cover Types Using LST and EVI}

In order to test whether LST and EVI can provide sufficient information to separate the four different land cover types, we applied linear discriminant analysis (LDA), using the LDA package in R software (Vienna University of Economics and Business, Vienna, Austria, http://www.r-project.org/, http://www.statmethods.net/advstats/discriminant.html). We used the overall seven-year means of EVI and LST as the two independent variables in our model to discriminate and classify the four different land covers. Prior probabilities of groups or a number of group variables were equal proportions $(25 \%$ or 200 samples for each land cover type). The resultant confusion matrix and error rate of the land cover classification was summarized.

\section{Results}

\subsection{Temporal Response of LST and EVI for Different Land Cover Types}

The 2006-2012 16-day averages and standard deviations of the MODIS EVI and LST show the intra-annual responses of the native forest, rubber plantation, mixed wooded/cleared areas and agriculture (Figure $4 \mathrm{a}-\mathrm{c}$ ). Figure 4 shows that each of these land cover types has distinctly different EVI and LST trajectories throughout the year.

Long-term annual means of EVI for native forest (0.47) and rubber plantation (0.45) were relatively similar (Figure 4a,b), higher than those of mixed wooded/cleared land (0.39) and agriculture (0.30) (Figure 4c,d).

A strong seasonal pattern of EVI is illustrated in all land cover classes except forest lands. The temporal EVI profile of native forests differed substantially from the other classes, with only weak seasonality. Although EVI values of native forests were highest and generally maintained throughout the year, there were higher variations in the signal during the rainy period (May-October) (Figure 4a). In contrast, EVI values of the other land covers increased from May to Oct (Figure $4 b-d$ ) and dropped to their minima between December-April (dry season). Rubber plantations and mixed wooded/cleared areas had similar seasonal patterns of EVI, but these land cover types could be distinguished in the dry season. EVI for the mixed wooded/cleared area was relatively low and closely similar to that of agricultural areas in the dry season, while rubber plantations still retained their greenness. The EVI was just lower than that of native forest lands.

The annual average LST of native forests was markedly lower than that of the other land cover types $\left(25^{\circ} \mathrm{C}\right.$ ) (Figure $\left.4 \mathrm{a}-\mathrm{c}\right)$. In contrast, annual average LST for the three other land cover types was relatively similar. Agricultural lands had the highest LST $\left(30^{\circ} \mathrm{C}\right)$, followed by that of rubber plantations $\left(29^{\circ} \mathrm{C}\right)$ and mixed wooded/cleared areas $\left(28.5^{\circ} \mathrm{C}\right)$. 

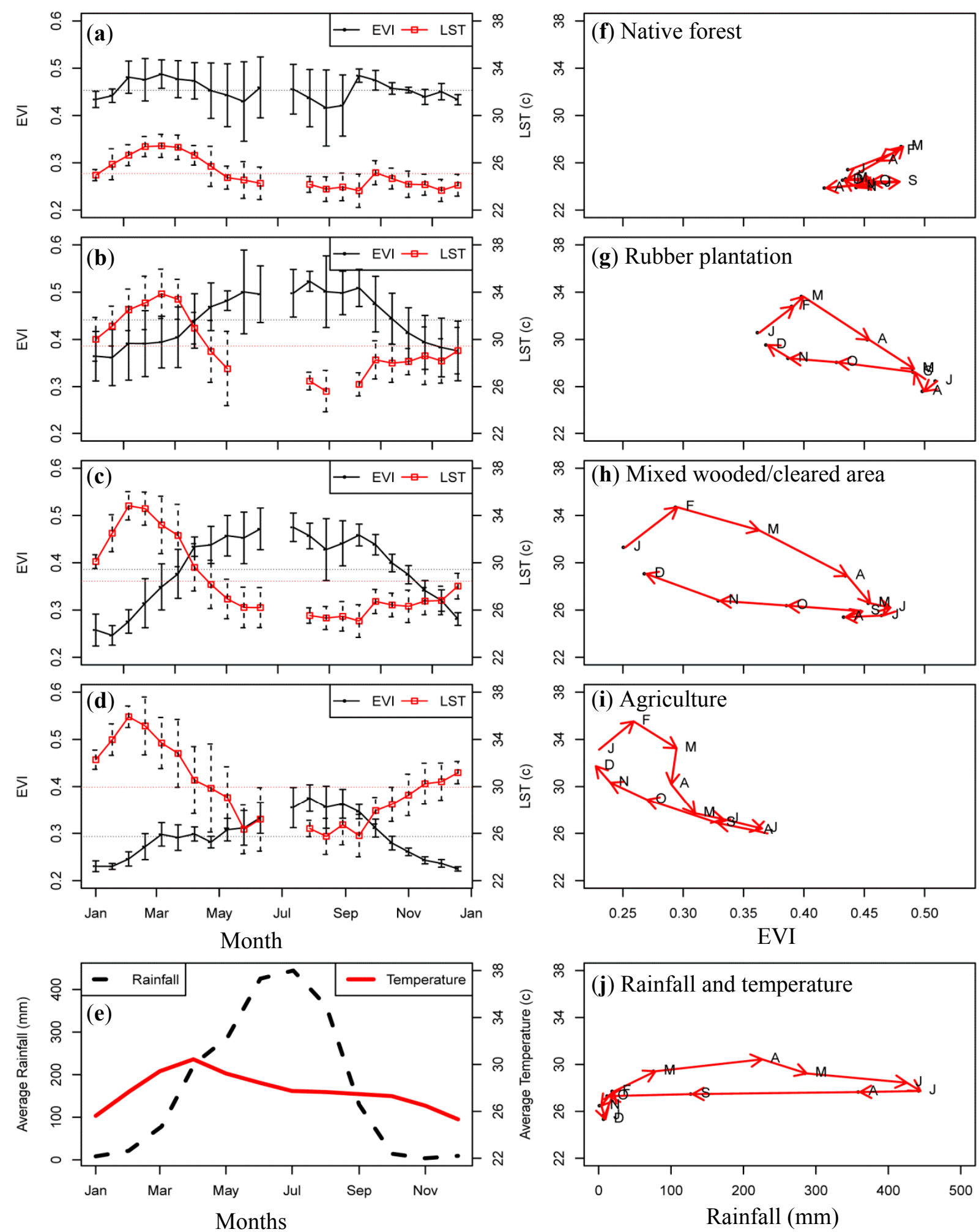

Figure 4. The average temporal responses of land surface temperature (LST) and enhanced vegetation index (EVI) from 2006-2012 in four different forest covers: (a) native forest, (b) rubber plantation, (c) mixed wooded/cleared area, (d) agriculture (the red line is LST in Celsius and its standard deviations (SD), while the black line is EVI and its SD), and (e) average temporal responses of rainfall and temperature, $(\mathbf{f}-\mathbf{i})$ are hysteresis patterns of LST/EVI for these land covers, (j) seasonal transitions of average rainfall and temperature. 
The seasonal pattern of LST was quite distinctive for each land cover. Native forest LST varied less throughout the year than that of the other land cover types (Figure 4a), with highest temperatures in late summer (February-April). The annual LST pattern of variation for the other three land covers showed some similarities. This pattern started to increase gradually from February-March and reached a peak (March-April). In contrast, LST was lowest during the rainy season. LST for all land cover types appeared to drop from May until October, and then repeated the seasonal cycle. Although the three land covers have similar patterns of LST, the period of LST maximum differed for each: in March for rubber plantations, in early February for mixed wooded/cleared and agricultural areas. The LST for agricultural lands tended to increase rapidly after its minimum in May-October (Figure 4d). This may be a result of rice harvesting activities, which start from November-January. Agricultural lands are left untouched until land preparation in May or June (depending on rainfall), followed by rice cultivation activities. The rice growing season usually starts from June-October.

\subsection{Monthly Transition of LST and EVI}

The monthly transitions of LST and EVI across the four different land covers in this study are exhibited in hysteresis plots (Figure $4 \mathrm{f}-\mathrm{i}$ ). These plots show the complex relationships and intra-annual variation of average LST and EVI for these land covers. The hysteresis loop behaviour of all land covers other than forests is in the same clockwise direction, but the loops differ in width. The similar pattern of rising and falling limbs in the LST and EVI trajectories tends to depend on seasonality. The width of the hysteresis loop for each land cover shows some variations resulting from the differences in LST and EVI over the course of the year.

The hysteresis loop for native forests shows characteristics that are quite different from the other plots. There is little change in EVI and LST across the seasons. However, the hysteresis loops for the other land covers depict pronounced seasonal transition cycles in their EVI/LST trajectory. LST in the falling limb has a higher corresponding EVI value, but in the rising limb LST has a lower corresponding EVI. This response type indicates changes in vegetation cover and land surface temperature during the annual seasonal cycle. However, the width of the hysteresis loops starts to decrease when EVI increases towards 0.45 or at LST of $28^{\circ} \mathrm{C}$ for rubber plantation and mixed wooded/cleared area.

The width of the hysteresis loops for three land covers (plantation, mixed wooded/cleared area and agriculture) differs and the loops occupy different spaces throughout the year. For mixed wooded/cleared lands, the hysteresis loop of LST/EVI is wider than those for the other land covers. This indicates more variations in LST and EVI in each month of the year (Figure 4h). Agriculture and plantations have a similar shape and width of LST/EVI trajectory (Figure 4i,g). This similar hysteresis pattern indicates a similar seasonal transition over time. However, their loops are located in different spaces, which show the different values of EVI/LST for these two land covers.

Figure 4e,j show the long-term averages of rainfall and temperature from 2006 to 2012 and their monthly transitions. The rainy season runs from May-October and the dry season from November to April. In the rainy season, an increase in EVI begins when rainfalls starts while LST starts to decrease, for example in rubber plantation, mixed wooded/cleared area and agriculture. A point of inflection of the hysteresis loops occurs at the maximum of EVI when LST is close to about $26{ }^{\circ} \mathrm{C}-28{ }^{\circ} \mathrm{C}$. During 
rainy period, the hysteresis loops for these three land covers remain stable until late September, as a result of less variation in EVI and LST.

\subsection{Discriminating the Different Land Cover Types Using LST and EVI}

The 2006-2012 long-term averages of LST and EVI for the 200 samples of the four land covers are illustrated in Figure 5. In general, the four land covers appear to be well separated in the plot, although there are some overlaps of EVI and LST among them. Forests have the highest values of long-term average of EVI but the lowest LST. Rubber plantation is the second highest for EVI and the second lowest for LST, followed by mixed wooded/cleared area. Agriculture shows the highest LST but with lower EVI than the others. Thus this comparison potentially enables separation or classification of these land cover classes.

Table 2 summarizes the result of linear discriminant analysis (LDA) on 800 samples of long-term averages of LST/EVI. The LDA output shows that LST and EVI can be used to classify the differences between the four land covers. The first discriminant function (LD1) achieved $83.37 \%$ separation between the four land covers, with the second discriminant function (LD2) improving the separation of the groups by a further $16.63 \%$. The variable with the largest standardized regression coefficients is the one that contributes most to the prediction of group membership. In our case, EVI is clearly the greater contributor to the discrimination of the four land covers (coefficients of 19.96 and 29.52 in LD1 and LD2), while those of LST were -0.53 and 1.00 respectively. The analysis revealed significant differences between the four land cover classes, with $86 \%$ overall accuracy in group classification. Misclassification occurred in only $14 \%$ for the samples overall.

The native forest had the highest accuracy of classification (95\%), followed by agriculture and plantation (92\% for both classes). However, mixed wooded/cleared class was lowest (67\%) (Table 2). Misclassification is seen in $4 \%$ of the native forest class, $7 \%$ of rubber plantation, $8 \%$ of agriculture and $24 \%$ of mixed wooded/cleared areas. The findings indicate that there is a high possibility of separating these land covers in tropical forests by using a combination of EVI and LST.

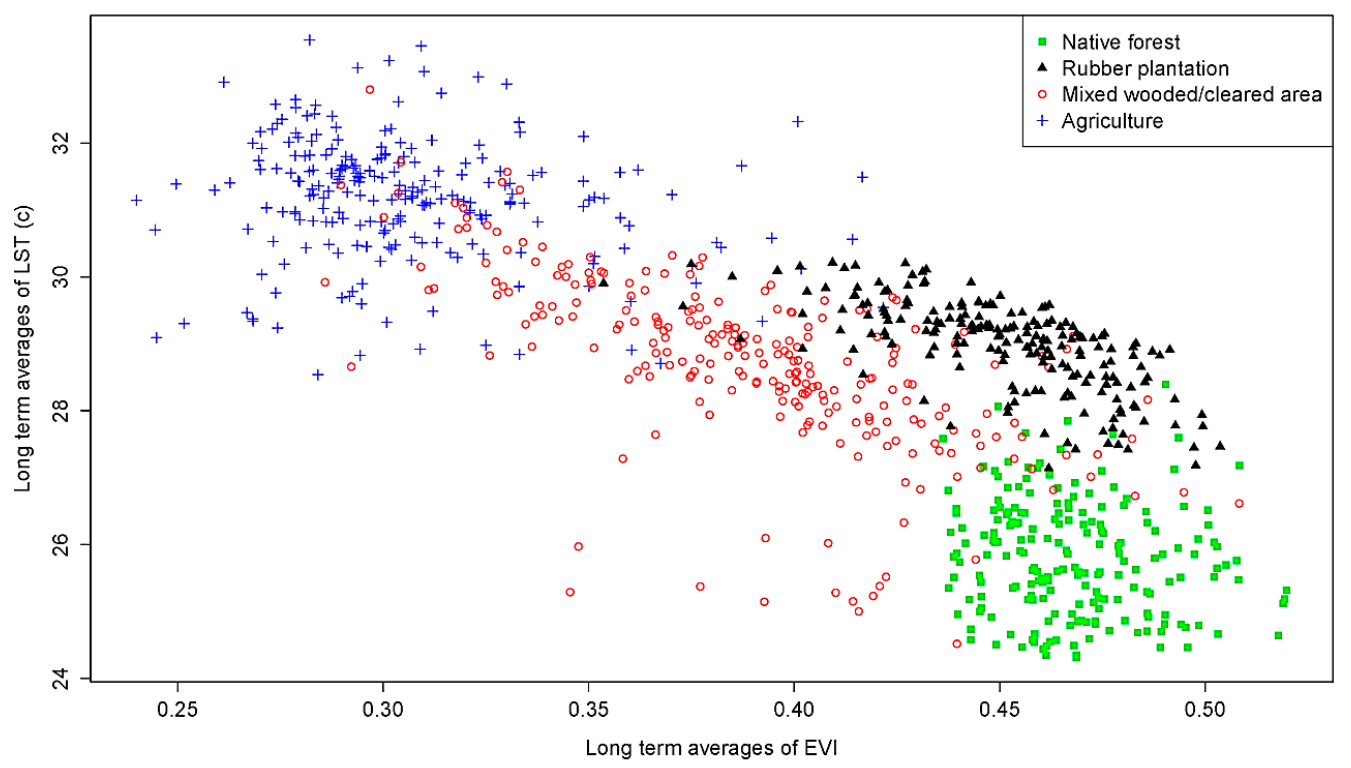

Figure 5. Long-term means (2006-2012) of LST and EVI for 800 MODIS samples within the four land cover types. 
Table 2. Summary of accuracy of classification predicted by LDA.

\begin{tabular}{ccccc}
\hline \multirow{2}{*}{ Actual } & \multicolumn{4}{c}{ Predicted } \\
\cline { 2 - 5 } & Agriculture & Native Forest & Plantation & Wooded/Cleared \\
\hline Agriculture & 0.92 & 0 & 0.03 & 0.05 \\
Native Forest & 0 & 0.95 & 0.04 & 0 \\
Plantation & 0 & 0 & 0.92 & 0.07 \\
Wood/Cleared & 0.14 & 0.1 & 0.09 & 0.67 \\
Overall accuracy & & & & $\mathbf{0 . 8 6}$ \\
\hline
\end{tabular}

\section{Discussion}

The analysis of LST and EVI from the MODIS time series in this study showed promise in characterizing the temporal responses of the four different land cover types. There are distinctly different EVI and LST temporal responses for these land covers. Dense vegetation cover such as native forest tends to have the lowest LST and the highest EVI throughout the year compared to the others. In contrast, agricultural land has the lowest EVI and the highest LST. This finding is similar to those of previous studies that non-forested areas have higher temperatures than forested lands $[19,23,26]$. This indicates that if vegetation cover is reduced due to clearance, it can contribute to an increase in heat energy transferred from the land surface. Our finding was also similar to that of Julien and Sobrino [29] which suggested that the closed canopy of tropical rainforests plays an important role in regulating and maintaining its LST constant throughout the year. Native forests maintain their leaves or canopies with adequate soil moisture and evapotranspiration throughout the year, allowing regulation of temperature. Temporal patterns of EVI and LST for rubber plantations and mixed wooded/cleared areas are similar in the rainy season, and these land covers can be distinguished only in the dry season, when there is less greenness in mixed wooded/cleared areas than rubber plantations. In the dry season, rubber plantation may have less greenness than native forests, but still more than mixed wooded/cleared areas. The mixed wooded/cleared area consists of some deciduous trees and great extent grassland in cleared areas. They become greener with higher EVI in the rainy season compared with the dry season.

We found a complex relationship between monthly averages of LST and EVI for the four land covers. The hysteresis loops of LST/EVI for three of the four land covers tended to be determined by seasonality, but not for forests (Figure $4 \mathrm{f}-\mathrm{i}$ ). The study shows that in the rainy season there is more photosynthesis activity of vegetation in the three land covers: rubber plantation, mixed wooded/cleared area and agriculture than in forests. Native forest shows higher EVI throughout the year, while the other land covers show seasonal patterns and more variations. This result suggests that the changes in vegetation covers in these three land covers are associated with changes in temperature and rainfall. In the hysteresis loops, we found that EVI increases as annual precipitation increases, but LST decreases. In contrast, when LST begins increasing and reaching its maximum in the dry period, EVI correspondingly decreases. However, this synchronization is not found in native forest. A similar result was also found in our previous research [27]. This suggests that rainfall and the resulting soil moisture and ground water from the wet season are sufficient for native forest plants to maintain almost full canopy during the dry season. There is approximately $300-450 \mathrm{~mm}$ of average precipitation per month. However, in dry season from November to April, there is the minimum growth of vegetation (or low EVI) due to low 
precipitation (less than $100 \mathrm{~mm}$ per month) and high temperature (up to $30{ }^{\circ} \mathrm{C}-35^{\circ} \mathrm{C}$ ). Between November and December, there is little or no rainfall and coolest temperatures. Mixed wooded/cleared areas consist of deciduous trees that usually lose their leaves during this period. This hysteresis behavior of LST/EVI was also found similarly in the West African woodlands [26].

The second research question concerned whether we can use the information of EVI and LST to classify the four land covers, which could allow us to identify and detect land cover changes in tropical regions. The LDA implemented on the long-term averages of LST/EVI shows a high classification accuracy for the four land cover classes (86\%). This accuracy was similar to a study of Julien, et al. [32] which used NDVI/LST for crop type classification (87\%), although Landsat-5 data time series and different approaches were used.

\section{Conclusions}

Detection of land cover change in tropical regions is an important application of remote sensing methods. Using a combination of MODIS EVI and LST may improve monitoring of changes in tropical vegetation cover. In this study, we examined the long-term averages (2006 to 2012) of EVI and LST time-series data 16-day composites and their intra-annual seasonal transitions for four different land covers in Lao tropical forests. Finally, we applied LDA to test whether the information from EVI and LST can be used to discriminate the major land covers in our study area. The results show that EVI contributed most to discrimination of cover types, with LST making a smaller contribution. When used in combination with LST and EVI provided detailed information on the characteristics and temporal responses of the four land covers. Using these two indices we can classify the four land covers with high overall accuracy ( $86 \%$ ). The outcomes of this study thus contribute to improving our understandings of tropical vegetation changes and responses to climate conditions. This study is a pathfinder toward providing an improved option for monitoring and detecting land cover changes in tropical regions.

\section{Acknowledgments}

This study was supported by the Australian Agency for International Development (AusAID). The authors particularly thank Dr. Margaret Cargill, from the University of Adelaide who is an academic English editor for this manuscript. Special acknowledgements are to the National Aeronautics and Space Administration (NASA) and the Google Earth ${ }^{\mathrm{TM}}$ enterprise for providing freely available images which were used for this research. We also thank the anonymous reviewers of the original manuscript, whose suggestions have helped improve this publication.

\section{Author Contributions}

Chittana Phompila designed the research, collected satellite data used and implemented data analysis. Megan Lewis assisted in the research design, data analysis and interpreting results, especially LDA outputs. Kenneth Clarke and Bertram Ostendorf helped to write Python and R scripts for image pre-processing or selecting data quality of MODIS EVI and LST data time series. All the authors worked on the interpretation of results, manuscript writing and revisions. 


\section{Conflicts of Interest}

The authors declare no conflict of interest.

\section{References}

1. Setiawan, Y.; Yoshino, K.; Prasetyo, L.B. Characterizing the dynamics change of vegetation cover on tropical forestlands using $250 \mathrm{~m}$ multi-temporal MODIS EVI. Int. J. Appl. Earth Obs. Geoinf. 2014, 26, 132-144.

2. Zuidema, P.A.; Baker, P.J.; Groenendijk, P.; Schippers, P.; van der Sleen, P.; Vlam, M.; Sterck, F. Tropical forests and global change: Filling knowledge gaps. Trends Plant Sci. 2013, 18, 413-419.

3. Thapa, R.B.; Shimada, M.; Watanabe, M.; Motohka, T.; Shiraishi, T. The tropical forest in South East Asia: Monitoring and scenario modeling using synthetic aperture radar data. Appl. Geogr. 2013, 41, 168-178.

4. Hou, Z.; Xu, Q.; Nuutinen, T.; Tokola, T. Extraction of remote sensing-based forest management units in tropical forests. Remote Sens. Environ. 2013, 130, 1-10.

5. Forkel, M.; Carvalhais, N.; Verbesselt, J.; Mahecha, M.; Neigh, C.; Reichstein, M. Trend change detection in NDVI time series: Effects of inter-annual variability and methodology. Remote Sens. 2013, 5, 2113-2144.

6. Prabakaran, C.; Singh, C.P.; Panigrahy, S.; Parihar, J.S., Retrieval of forest phenological parameters from remote sensing-based NDVI time-series data. Curr. Sci. 2013, 105, 795-802.

7. Hmimina, G.; Dufrêne, E.; Pontailler, J.Y.; Delpierre, N.; Aubinet, M.; Caquet, B.; de Grandcourt, A.; Burban, B.; Flechard, C.; Granier, A.; Gross, P.; Heinesch, B.; Longdoz, B.; Moureaux, C.; Ourcival, J.-M.; Rambal, S.; Saint André, L.; Soudani, K. Evaluation of the potential of MODIS satellite data to predict vegetation phenology in different biomes: An investigation using ground-based NDVI measurements. Remote Sens. Environ. 2013, 132, 145-158.

8. Mildrexler, D.J.; Zhao, M.; Heinsch, F.A.; Running, S.W. A new satellite-based methodology for continental-scale disturbance detection. Ecol. Appl. 2007, 17, 235-250.

9. Mildrexler, D.J.; Zhao, M.; Running, S.W. Testing a MODIS global disturbance index across North America. Remote Sens. Environ. 2009, 113, 2103-2117.

10. Sobrino, J.A.; Julien, Y. Trend analysis of global MODIS-Terra vegetation indices and land surface temperature between 2000 and 2011. IEEE J. Sel. Top. Appl. Earth Obs. Remote Sens. 2013, 6, 2139-2145.

11. Coops, N.C.; Wulder, M.A.; Iwanicka, D. Large area monitoring with a MODIS-based Disturbance Index (DI) sensitive to annual and seasonal variations. Remote Sens. Environ. 2009, $113,1250-1261$.

12. Huete, A.R.; Didan, K.; Shimabukuro, Y.E.; Ratana, P.; Saleska, S.R.; Hutyra, L.R.; Yang, W.; Nemani, R.R.; Myneni, R. Amazon rainforests green-up with sunlight in dry season. Geophys. Res. Lett. 2006, 33, 1-4.

13. Huete, A.R.; Restrepo-Coupe, N.; Ratana, P.; Didan, K.; Saleska, S.R.; Ichii, K.; Panuthai, S.; Gamo, M. Multiple site tower flux and remote sensing comparisons of tropical forest dynamics in Monsoon Asia. Agric. For. Meteorol. 2008, 148, 748-760. 
14. Ma, X.; Huete, A.; Yu, Q.; Coupe, N.R.; Davies, K.; Broich, M.; Ratana, P.; Beringer, J.; Hutley, L.B.; Cleverly, J.; Boulain, N.; Eamus, D. Spatial patterns and temporal dynamics in savanna vegetation phenology across the North Australian Tropical Transect. Remote Sens. Environ. 2013, 139, 97-115.

15. Senf, C.; Pflugmacher, D.; van der Linden, S.; Hostert, P. Mapping rubber plantations and natural forests in Xishuangbanna (Southwest China) using multi-spectral phenological metrics from MODIS time series. Remote Sens. 2013, 5, 2795-2812.

16. Zhang, X.; Friedl, M.A.; Schaaf, C.B.; Strahler, A.H.; Liu, Z. Monitoring the response of vegetation phenology to precipitation in Africa by coupling MODIS and TRMM instruments. J. Geophys. Res. 2005, 110, 1-14.

17. Jiménez-Muñoz, J.C.; Sobrino, J.A.; Mattar, C.; Malhi, Y. Spatial and temporal patterns of the recent warming of the Amazon forest. J. Geophys. Res.: Atmos. 2013, 118, 5204-5215.

18. Herdianto, R.; Paik, K.; Coles, N.A.; Smettem, K. Transitional responses of vegetation activities to temperature variations: Insights obtained from a forested catchment in Korea. J. Hydrol. 2013, 484, 86-95.

19. Mildrexler, D.J.; Zhao, M.; Running, S.W. A global comparison between station air temperatures and MODIS land surface temperatures reveals the cooling role of forests. J. Geophys. Res. 2011, $116,1-15$.

20. Coops, N.C.; Duro, D.C.; Wulder, M.A.; Han, T. Estimating afternoon MODIS land surface temperatures (LST) based on morning MODIS overpass, location and elevation information. Int. J. Remote Sens. 2007, 28, 2391-2396.

21. van Leeuwen, T.T.; Frank, A.J.; Jin, Y.; Smyth, P.; Goulden, M.L.; van der Werf, G.R.; Randerson, J.T. Optimal use of land surface temperature data to detect changes in tropical forest cover. $J$. Geophys. Res. 2011, 116, G02002.

22. Yue, W.; Xu, J.; Tan, W.; Xu, L. The relationship between land surface temperature and NDVI with remote sensing: Application to Shanghai Landsat 7 ETM+ data. Int. J. Remote Sens. 2007, 28, 3205-3226.

23. Chernetskiy, M.; Pasko, I.; Shevyrnogov, A.; Slyusar, N.; Khodyayev, A. A study of forest vegetation dynamics in the south of the Krasnoyarskii Krai in spring. Adv. Space Res. 2011, $48,819-825$.

24. Stroppiana, D. Seasonality of MODIS LST over southern Italy and correlation with land cover, topography and solar radiation. Eur. J. Remote Sens. 2014, 47, 133-152.

25. Ehrlich, D.; Lambin, E.F. Broad scale land-cover classification and interannual climatic variability. Int. J. Remote Sens. 1996, 17, 845-862.

26. Lambin, E.F.; Ehrlich, D. The surface temperature-vegetation index space for land cover and land-cover change analysis. Int. J. Remote Sens. 1996, 17, 463-487.

27. Lambin, E.F.; Ehrlich, D. Land-cover changes in Sub-Saharan Africa (1982-1991): Application of a change index based on remotely sensed surface temperature and vegetation indices at a continental scale. Remote Sens. Environ. 1997, 61, 181-200.

28. Nemani, R.R.; Running, S.W. Land cover characterization using multitemporal red, near-IR, and thermal-IR data from NOAA/AVHRR. Ecol. Appl. 1997, 7, 79-90. 
29. Julien, Y.; Sobrino, J.A. The yearly land cover dynamics (YLCD) method: An analysis of global vegetation from NDVI and LST parameters. Remote Sens. Environ. 2009, 113, 329-334.

30. Samanta, A.; Ganguly, S.; Vermote, E.; Nemani, R.R.; Myneni, R.B. Interpretation of variations in MODIS-measured greenness levels of Amazon forests during 2000 to 2009. Environ. Res. Lett. 2012, 7, 1-12.

31. Grogan, K.; Fensholt, R. Exploring patterns and effects of aerosol quantity flag anomalies in MODIS surface reflectance products in the tropics. Remote Sens. 2013, 5, 3495-3515.

32. Julien, Y.; Sobrino, J.A.; Jiménez-Muñoz, J.C. Land use classification from multitemporal Landsat imagery using the yearly land cover dynamics (YLCD) method. Int. J. Appl. Earth Obs. Geoinf. 2011, 13, 711-720.

(C) 2015 by the authors; licensee MDPI, Basel, Switzerland. This article is an open access article distributed under the terms and conditions of the Creative Commons Attribution license (http://creativecommons.org/licenses/by/4.0/). 